\title{
International medical travel and the politics of therapeutic place-making in Malaysia
}

\author{
Meghann Ormond ${ }^{1}$
}

Received: 20/07/2011

${ }^{1}$ Cultural Geography Group, Wageningen University, phone: +31 317486199, e-mail: meghann.ormond@wur.nl

Supervisor: Dr Matthew Sothern

Institution awarding the Ph. D. Degree: University of St Andrews (Scotland, UK)

Date of defence: $18^{\text {th }}$ November 2010

(C) 2011 International University College. All rights reserved

Citation: Ormond, M. (2011), International medical travel and the politics of therapeutic placemaking in Malaysia. Doctoral dissertation summary. European Journal of Tourism Research 4(2), pp. 221-225

\section{Goal and objectives of the dissertation Goal}

This dissertation's examination of international medical travel (IMT) - where people cross national borders in the pursuit of healthcare builds on an intersection of feminist and postcolonial scholarship that seeks to challenge embedded assumptions about the sources, directions and political value of care. In so doing, it contributes to contemporary social science debates on the role of mobility in questions of care, responsibility and interdependence. With many of the countries currently being promoted as IMT destinations holding 'developing' status, IMT poses a significant challenge to popular assumptions about who provides and receives care since it inverses and diversifies presumed directionalities of care. Taking as a point of departure the notion that the boundaries to the terrains and subjects engaged in the provision and receipt of care are constantly in flux, the dissertation examines the discursive and material positioning of Malaysia as one of the world's most prominent IMT destinations at a moment when the status of the nation-state is undergoing profound transformation.

\section{Objectives}

The dissertation seeks to demonstrate how 'Malaysia' gets positioned as a hospitable destination within a range of imagined geographies of care. The extension of care through the harnessing of IMT - can serve as a place-making technology to re-imagine the state as a provider and protector within a globalising marketplace in which care, increasingly commoditised, is tied to the production of new political, social, cultural and economic geographies. This signals a fundamental reterritorialisation of care aligned with the pursuit of greater 'global' economic, political, social and cultural integration and legitimacy that reconfigures the relevance of the nation-state.

In order to trace broader changes between countries, groups and individuals as they 
International medical travel and the politics of therapeutic place-making in Malaysia. Doctoral dissertation summary.

negotiate their positions within increasingly commodified relationships of care, I explore how IMT flows and their selective harnessing by the state and the private sector become part of a new postcolonial nation-building project in Malaysia by asking the following questions:

- What does the 'extension of caring' through the provision of private healthcare to noncitizens in Malaysia accomplish, and what sorts of power relations does this expedite?

- What 'Malaysia' is put 'on the map' to qualify for 'world-class' IMT destination status?

- Which characteristics are promoted as national credentials for expert care-giving and which are suppressed, ignored or rendered obsolete?

\section{Methodology}

From late 2007 to early 2008, 49 single indepth, semi-structured interviews, lasting between 40 minutes and three hours each, were held with respondents in Kuala Lumpur, Penang and Malacca to better grasp how they conceptualise IMT flows and responses and act to influence the course of the industry's development within Malaysia:

- Top-level executives and administratives (e.g., CEOs, directors, senior managers, board members and advisors) for governmental, private and not-for-profit bodies;

- Research, business development, marketing, policy, public relations and customer service executives and officers;

- Medical travel facilitators and medical professionals.

An interview guide covering the general development of the IMT industry in Malaysia, changes in the pursuit and provision of medical care and the overall customer base was loosely employed with all interviewees as a point of departure to prompt open-ended responses and discussion.

Discourse analysis of the interview transcripts and the secondary (e.g., international and domestic media coverage, private-sector and governmental documents and statistics) data gathered during the fieldwork period was then undertaken in order to interpret claims made to specific forms of care expertise, the construction of such expertise and the manners in which select others are invited to draw upon it.

\section{Results}

This dissertation has sought to demonstrate how a state's legitimacy is now increasingly derived from successfully attracting and facilitating investment by positioning its territory and subjects as a unique and privileged 'package', simultaneously containerised and globally integrated such that its territorialised differences and selective openness to particular flows of people and capital may foster strategic alliances deemed key to 'national' development interests.

The discursive scopes and practices of care have always been in flux, with the imagined boundaries to the terrains and subjects engaged in the provision and receipt of care changing significantly over time. Healthcare provision has long served as a technology for controlling and forging alliances across political regimes and economic phases. Increasingly in the business of getting business for business, we have seen the ways in which the postdevelopmental Malaysian state is implied not only in investing in, endorsing and showcasing the 35 private hospitals selected for foreign patient-consumers but also in developing national healthcare accreditation schemes, reregulation on the heels of deregulation, incentives to lure back experienced expat Malaysian medical professionals to contribute to the development of their 'homeland' and educational programmes to train a crop of young professionals and provide them with competitive employment opportunities to stem international brain-drain. This intensification of transnational, intersectoral and public-private linkages aids the state's bid for Malaysia to be a player within the global knowledge economy while insinuating itself into the very heart of the action.

\section{Theoretical conclusions}

In light of rapidly growing academic interest in IMT, the dissertation's focus on the political framings of transnational mobilities and claims to cultural competence makes an empirically- 
grounded theoretical contribution at a moment in which both critical theoretical engagement and in-depth empirical material are widely acknowledged to be sorely missing in literature on IMT. Calling attention to the relational politics of healthcare provision, it contributes to thinking on broader theoretical concerns with questions of care, interdependence and mobility. At the same time, it also contributes to a growing body of work that decentres the focus from Western industry interests and medical travellers through acknowledging the significance and nuanced diversity of other populations constituting IMT flows and destinations. It takes into account broader shifts underway in healthcare provision and its regulation, recognising IMT destinations not as passive receptacles or victims of Western hegemonic interests in IMT but as active providers, negotiating complex change in health governance and the benefits and challenges of extending care beyond national borders.

\section{Practical application of the dissertation}

The dissertation offers a detailed case study through which to relate to broader debates concerned with the societal consequences of, and the development of effective policy responses to, the privatisation and globalisation of healthcare. Its findings will be of interest to researchers and public policy-makers involved in healthcare, tourism, trade and development issues, NGOs engaged with questions of healthcare privatisation and local development strategies, and groups in public-private partnerships charged with designing and implementing promotional strategies for harnessing international medical travel in their jurisdictions.

\section{Content of the dissertation}

\section{Abstract of chapter one}

The introduction (Chapter 1) situates the Malaysian case study at the fruitful crosssection of a range of literatures: international medical travel (IMT); the role of cross-border mobility in the construction of identity; care and hospitality; therapeutic landscapes; placebranding and medical diplomacy. It lays out the conceptual tools to be used in a critical interpretation of claims made to specific forms of care expertise, the construction of such expertise and the manners in which select others are invited to draw upon it - in other words, through whom, for whom, how and where care exchanges are sanctioned - in order to be able to unravel the complex processes and layers of identity politics that serve as the foundation for relationships which determine the conditions for care.

\section{Abstract of chapter two}

Chapter 2 is dedicated to the methodology employed in the dissertation.

\section{Abstract of chapter three \\ Shifting subjects and territories of healthcare}

This chapter situates the promotion of Malaysia as an IMT destination within a genealogy of healthcare provision contextualised in relation to four territorialisations of development policy. Starting with the colonial period, it then goes on to trace the shift in postcolonial development approaches from an inward-looking 'developmental' focus on nation-building to a more outwardly-articulated 'postdevelopmental' agenda concentrated on attracting global capital for survival through public-private partnerships. With the harnessing of IMT through these partnerships framed as a response to the discursively 'unavoidable' external pressures of economic globalisation on Malaysia, the chapter argues that IMT's inclusion in the development framework led to a new discursive space in which IMT came to play a prominent role in the country's development imaginary that has extended well beyond its own economic contribution. The promotion of IMT to Malaysia has worked as a model and 'test-bed' in which the state and private sector experiment with cultivating a domestic healthcare system responsive to neoliberal subjects and dissuading reliance on a 'démodé' public healthcare infrastructure characteristic of a developmental state.

\section{Abstract of chapter four \\ Plotting Malaysia on the global healthcare map This chapter examines some of the neoliberal governance techniques that shape IMT destinations and plot them on a map of 'international' legitimacy suited to the standards demanded by Western healthcare consumers}


and corporate investment. Situating IMT within the shift from 'international' healthcare governance, with its focus on the state's responsibility to ensure the health of its subjects, to 'global' healthcare governance, it takes into account the growing involvement of non-state actors in healthcare provision and the spectrum of public/private relations in healthcare that, with economic liberalisation, transcend and complicate the 'traditional' territorialisation of the nation-state. Because this neoliberal rescripting of healthcare requires that subjects, both providers and consumers, be marketised and responsibilised, the chapter then goes on to examine the intermediaries that govern and regulate healthcare as a commodity and that shape consumer recognition of, and demand for, new markers of quality and legitimacy in the therapeutic landscapes of IMT. It takes stock of the technologies of this (incomplete) 'bull-dozing' within the Malaysian IMT landscape: the categorisation and quantification of IMT destinations' quality and flows that facilitate international industry-wide comparison; the standardisation of IMT medical facilities' structures, processes and outcomes via pressure for internationally-recognised accreditation; partnerships with world-famous medical facilities; and the promotional deployment of medical professionals' credentials earned in prestigious Western educational and training establishments.

\section{Abstract of chapter five \\ Strategic cosmopolitanism and 'Muslim-friendly' care expertise}

This chapter focuses on the role of cultural competence in the customer-focused care that is central to the success of IMT. It examines highly contested identity politics underlying claims to culturally-specific care expertise and the interpellation of 'strategic cosmopolitan' Malaysian care-giving subjects. In its engagement with global capital, the postdevelopmental state has begun to revalue and identify national diversity as central to Malaysian identity. While a multi-ethnic, multilingual and multi-religious Malaysia had been framed as particularly threatening to nationbuilding efforts in the early period following the country's independence, recent decades have witnessed growing state awareness of the economic value of its ethnically diverse population, now deemed capable of plugging 'Malaysia' into lucrative transnational flows and networks. This chapter considers the focus by social actors in the Malaysia IMT industry on specific patient-consumer markets and examines how 'strategic cosmopolitan' cultural credentials are constituted and deployed in promotional strategies to attract medical travellers of select origins by tapping into a range of trans-, supra-, sub- and post-national belongings, alliances and values. It does this by offering an analysis of 'strategic cosmopolitan' claims to, and the cultivation of, Malaysia's modern, progressive 'Islamic credentials' in the realm of IMT as a way in which to plug the country's majority Muslim population into an increasingly mobile transnational Muslim community.

\section{Abstract of chapter six \\ 'Complementarities' and regionalised lands- capes of medical travel}

This chapter explores IMT's discursive and material contributions to the redrawing of development terrains - specifically crossborder development regions, triangles and corridors - as test-beds of graduated sovereignty. It contemplates the significance of regional cross-border healthcare in subnational, national and regional development agendas. Shifting the pursuit and provision of healthcare outside of the national domain leads to re-conceptualisations of healthcare's ties to citizenship and of the significance of regionalised belongings and affiliations. Healthcare plays an important role in extending Malaysia's political, cultural and socioeconomic spheres of influence by establishing and reinforcing regional 'complementarities' within ASEAN. Two cross-border regional case studies contextualise IMT industry emphasis on the 'sibling-like' cultural, linguistic and physical proximity between (parts of) Malaysia and its neighbours from Indonesia and Singapore that have turned to private healthcare providers in Malaysia for affordable, quality care. At the same time, they point to the persistent, significant economic differentials that primarily drive (highly uneven) development within these regions. 


\section{Abstract of chapter seven}

The conclusion (Chapter 7) summarises the research findings and reflects on the strategicrelational logic of care provision and the extension of hospitality by the state in the context of increasingly globalised flows. It contemplates how 'caring for' specific categories of non-citizens gets used to reconfigure the role of the state as expert in cultivating and managing the resources and skills relevant and attractive to mobile capital. A state's legitimacy now appears to be increasingly derived from successfully attracting and facilitating global investment, positioning its territory and subjects as a unique and privileged 'package', simultaneously containerised and globally integrated such that its territorialised differences and selective openness to particular flows of people and capital may foster strategic alliances deemed key to 'national' development interests. The chapter concludes with considerations of how the provision of healthcare in the scope of IMT can speak more broadly to the evolving political work that the selective extension of care and hospitality - in its many forms - accomplishes over time and space. 